\title{
Cannabis and Pain: A Clinical Review
}

\author{
Kevin P. Hill, ${ }^{1,2, *}$ Matthew D. Palastro, ${ }^{1}$ Brian Johnson, ${ }^{3}$ and Joseph W. Ditre ${ }^{4}$
}

\begin{abstract}
Introduction: Cannabis has been used for medical purposes across the world for centuries. As states and countries implement medical and recreational cannabis policies, increasing numbers of people are using cannabis pharmacotherapy for pain. There is a theoretical rationale for cannabis' efficacy for pain management, although the subjective pain relief from cannabis may not match objective measurements of analgesia. As more patients turn to cannabis for pain relief, there is a need for additional scientific evidence to evaluate this increase.

Materials and Methods: Research for this review was performed in the PubMed/National Library of Medicine database.

Discussion: Preclinical studies demonstrate a narrow therapeutic window for cannabis as pharmacotherapy for pain; the body of clinical evidence for this indication is not as extensive. A recent meta-analysis of clinical trials of cannabis and cannabinoids for pain found modest evidence supporting the use of cannabinoid pharmacotherapy for pain. Recent epidemiological studies have provided initial evidence for a possible reduction in opioid pharmacotherapy for pain as a result of increased implementation of medical cannabis regimens.

Conclusion: With increased use of medical cannabis as pharmacotherapy for pain comes a need for comprehensive risk-benefit discussions that take into account cannabis' significant possible side effects. As cannabis use increases in the context of medical and recreational cannabis policies, additional research to support or refute the current evidence base is essential to attempt to answer the questions that so many healthcare professionals and patients are asking.
\end{abstract}

Keywords: anandamide; cannabidiol; cannabinoids; endocannabinoid; pain; THC

\section{Introduction: Promising Compounds, Changing Landscape}

Cannabis has been used around the world for centuries and the purpose for its use has varied throughout that time. ${ }^{1}$ However, the utilization of cannabis for medicinal purposes has been consistent. Starting with the Chinese around 2900 B.C., many civilizations have transcribed their use of cannabis for a variety of conditions, from joint pain and muscle spasms to conditions such as gout and malaria. ${ }^{1}$ While cannabis has been deployed medicinally for myriad medical conditions, the scientific rationale for its efficacy for these conditions is, in many cases, not clear. Four thousand years later, scientists are still trying to determine the exact medical conditions, if any, cannabis is effective in treating.

Research into cannabis and its uses has been hindered by a debate over its legality. ${ }^{2}$ In 1976, the United States Controlled Substances Act classified cannabis as a Schedule I drug, meaning that it has a high potential for abuse and no accepted medical uses. However, as of March 2017, 28 states and the District of Columbia have enacted laws allowing the medical use of cannabis and 8 states, plus the District of Columbia, have legalized recreational use of cannabis. ${ }^{3}$ The accepted

${ }^{1}$ Division of Alcohol and Drug Abuse, McLean Hospital, Belmont, Massachusetts.

${ }^{2}$ Harvard Medical School, Boston, Massachusetts.

${ }^{3}$ State University of New York Upstate Medical University, Syracuse, New York.

${ }^{4}$ Department of Psychology, Syracuse University, Syracuse, New York.

*Address correspondence to: Kevin P. Hill, MD, MHS, Division of Alcohol and Drug Abuse, McLean Hospital, 115 Mill Street, Belmont, MA 02478, E-mail: khill@mclean.harvard.edu

(C) Kevin P. Hill et al. 2017; Published by Mary Ann Liebert, Inc. This is an Open Access article distributed under the terms of the Creative Commons Attribution License, which permits unrestricted use, distribution, and reproduction in any medium, provided the original work is properly cited. Mary Ann Liebert, Inc. offers reprint services for those who want to order professionally produced copies of articles published under the Creative Commons Attribution (CC BY) license. To obtain a price quote, email Reprints@liebertpub.com. Please include the article's title or DOI, quantity, and delivery destination in your email. 
conditions vary from state to state, in large part, due to the lack of randomized placebo-controlled studies researching the efficacy of cannabis for specific ailments. ${ }^{4}$ Despite a paucity of standardized and controlled trial research to evaluate the short- and long-term health outcomes of cannabis use, all states are consistent in including chronic pain as one of the conditions for which cannabis is an approved pharmacotherapy. Indeed, pain relief is the most commonly cited reason for the medical use of cannabis. ${ }^{4-6}$

Whether cannabis is the best treatment for pain or not, many patients around the world believe that cannabis has helped them with their pain. ${ }^{7}$ As more and more states legalize cannabis for medicinal uses, a greater number of patients will ask their healthcare provider if it would be an effective treatment for their condition. Healthcare providers are in a difficult situation: there are only two cannabinoids currently approved by the United States Food and Drug Administration, and state regulations require them to recommend cannabis broadly, leaving the details about cannabis strains and dosing to be determined at the dispensaries. Interest in the use of cannabis for pain may be further catalyzed by a recent report put forth by the National Academies Committee on the Health Effects of Marijuana, ${ }^{8}$ in which the authors concluded that there is "conclusive or substantial evidence" that cannabis is effective for the treatment of chronic pain in adults. Furthermore, even if physicians do not recommend cannabis for their own patients, they should at least be educated regarding the extensive effects of cannabis. Unfortunately, many patients currently use cannabis to treat a host of medical problems and do so without contacting their healthcare provider. ${ }^{7}$ Healthcare professionals need to be prepared to answer questions regarding cannabis use and the potential effect it would have on each patient's treatment.

\section{Cannabis and pain: a brief history}

The utilization of cannabis for pain can be traced back to ancient Chinese texts, dating to 2900 B.C. The Shennong Ben Cao Jing, a Chinese encyclopedia on agriculture and medicine, contains the oldest written record of cannabis as a medicine, recommending cannabis for constipation, rheumatic pain, female reproductive tract disorders, and malaria. ${ }^{9}$ Furthermore, the plant was used in conjunction with wine to anesthetize patients during surgical procedures. ${ }^{10}$ The Chinese mostly utilized cannabis seeds that contain very low levels of delta-9-tetrahydrocannabinol $\left(\Delta^{9} \mathrm{THC}\right)$, one of the main compounds in cannabis thought to have therapeutic effects. ${ }^{10}$
Around 1000 year B.C., more parts of the cannabis plant started to be used medicinally in India. The female plant's flowers were utilized and three different preparations of cannabis with varying degrees of potency were developed. ${ }^{9}$ The strongest preparations were used as an analgesic, hypnotic, tranquilizer, antispasmodic, and anti-inflammatory agent. ${ }^{11,12}$ It was not until the early 19th century that cannabis started to be explored in Western medicine. ${ }^{13}$

Although the use of cannabis as a medicine in western cultures started off slowly, by the end of the 19th century, over 100 publications on medicinal cannabis were published in Europe and the United States. ${ }^{14}$ Within that time, the medical indications for cannabis mostly focused on its hypnotic and analgesic effects. Since then, medical cannabis use has waxed and waned due to legal restrictions as well as the difficulty with replicating its effects between individuals. ${ }^{11,15}$ Since the 1960s, both recreational cannabis use and medicinal cannabis use have increased rapidly in the United States. In 2015, an estimated 22.2 million Americans aged 12 or older were current users of cannabis, which corresponds to $8.3 \%$ of the U.S. population aged 12 or older. ${ }^{16}$ Recently, research into cannabis expanded exponentially and the use of cannabis for pain became one of the most widely studied subtopics. ${ }^{17}$

There are two ways to consider the rationale for cannabis pharmacotherapy for pain, conceptually and according to the evidence base. In this review, we will examine both.

\section{Materials and Methods}

Standard searches of the PubMed/National Library of Medicine database for the listed keywords and references from literature for pertinence to cannabis and the clinical management of pain were undertaken.

The subjective experience of pain

Pain has long been characterized as a subjective experience encompassing sensory-physiological, motivationalaffective, and cognitive-evaluative components. ${ }^{18}$ Approximately, 100 million U.S. adults are encumbered by chronic pain ${ }^{19,20}$; pain motivates greater than $50 \%$ of all annual physician visits, ${ }^{21}$ and recent estimates indicate a pain-related financial burden in excess of $\$ 600$ billion in annual healthcare costs and lost productivity. ${ }^{19}$ The three main pain systems are nociceptive, neuropathic, and central. ${ }^{22}$ Nociceptive pain is caused by damage to body tissue and is usually described as sharp, aching, or throbbing pain. In response to tissue injury, invading immune cells secrete histamine, serotonin, 
bradykinin, prostaglandin, elevated levels of tumor necrosis factor alpha, interleukin 1 beta, interleukin 6 , and interleukin $17 .^{23}$ Signals of tissue injury are carried by fine $\mathrm{C}$ - and A-gamma peripheral nerves to dorsal root ganglia, up the spinothalamic track to the thalamus, and then on to the cortical area. ${ }^{24}$ It is important to note that this is the only nociceptive system by which the survival value of pain to alert the organism to potential or occurring tissue damage exists. Nociceptive pain has warning and defensive properties. The other two pain systems, neuropathic and central, involve nonfunctional pain signals with disease involving the interpreting system. ${ }^{25,26}$

Neuropathic pain is caused by damage to sensory or spinal nerves, which send inaccurate pain messages to higher centers. ${ }^{26}$ For example, in diabetic neuropathy, the origin of foot pain is not in the tissue, but rather, the peripheral nerves. The disease attacks the peripheral nerves, resulting in an aberrant signal interpreted by the brain as pain in the feet. Centralized pain is the result of amplification of peripheral signals due to persistent central nervous system dysfunction. ${ }^{22}$ Pain may be present despite a lack of a clear peripheral cause. A classic example is fibromyalgia. ${ }^{25}$ The Clauw metaphor is that the electric guitar is a quiet instrument until the amplifier (brain) is plugged in. The central nervous system amplification makes the pain impossible to ignore.

The complex nature of pain can make it difficult to understand another's pain. First, there are many genetic variants of pain, such as alleles of the SCN9A gene. SCN9A variants determine typical pain experiences, heightened pain, and rarely, the inability to feel pain by regulating the expression of voltage-gated sodium channel $\mathrm{Na}(\mathrm{v}) 1.7$ $\mathrm{mRNA}$, a resulting protein that is an important contributor to generation and conduction of action potentials of nociceptive neurons of dorsal root ganglia. ${ }^{24}$ Low $\mathrm{Na}(\mathrm{v}) 1.7$ results in low initiation and propagation of pain signals, and therefore high pain thresholds while high $\mathrm{Na}(\mathrm{v}) 1.7$ would result in exaggerated pain sensitivity.

Second, the relationship of the observer to the pain experiencer is relevant to the observer's ability to gauge the extent of the experiencer's pain. When one feels close to another, one is more concerned with another's pain, in part, because different brain areas are activated by empathic connection versus when considering the pain experience of a stranger. ${ }^{27}$ For example, emergency physicians were thrice more likely to prescribe opioids to patients in motor vehicle accidents who had not completed high school than patients who shared their graduate level of education, suggest- ing that empathy and concern about prescribing a drug with addictive potential may affect the decision. ${ }^{28}$

Finally, pain is an affect, or a subjective aspect of an emotion. However, an affect is a combination of innate endowment, childhood and adult history as metabolized through the consciousness of the person, and interpersonal relatedness. Pain experienced by a person with the normal SCN9A gene endowment might be dramatically different from pain caused by the same peripheral injury in someone with the high pain SCN9A gene variant suffering from serious psychiatric disorders such as major depressive disorder or borderline personality disorder. ${ }^{29,30}$ These individuals' responses to pain will likely be different.

\section{Substances Used for Pain}

Cannabis is rarely the first drug that a patient takes to mitigate pain. Nonsteroidal anti-inflammatory drugs (NSAIDs) inhibit pain by addressing local tissue inflammation. They inhibit cyclooxygenase (COX), an enzyme required to make the vasodilator prostaglandin. Therefore, the painful swelling of peripheral tissues is decreased. NSAIDs can be used daily for prolonged periods to manage inflammatory conditions such as arthritis. ${ }^{31}$

Alcohol also has an extensive history as a substance used in response to pain, and epidemiological data substantiate a high co-occurrence of pain and alcohol use. ${ }^{32}$ For example, past-month pain is highly prevalent among individuals seeking treatment for alcohol use disorder (AUD; e.g., 73\%), ${ }^{33}$ and chronic pain patients are up to $60 \%$ more likely to endorse heavy drinking and/ or meet diagnostic criteria for AUD, even after accounting for concurrent psychopathology and other substance use problems. ${ }^{34-36}$ Although there is some evidence that drinking alcohol can confer short-term pain inhibition, such effects may require consumption at doses that exceed guidelines for moderate daily use, and the development of tolerance would likely require more alcohol to achieve the same degree of acute analgesia. ${ }^{37}$ There is also converging evidence ${ }^{38}$ that periods of abstinence following chronic alcohol consumption tend to be associated with increased sensitivity to pain, which in turn could promote relapse to drinking. Alcohol is mood-altering and addictive, thus physicians do not recommend that patients use alcohol to treat either acute or chronic pain.

Like alcohol, nicotine and tobacco smoking have long been implicated in the amelioration of pain. ${ }^{39,40}$ Prevalence estimates indicate that individuals with chronic pain (vs. no chronic pain) are about twice as likely to be current smokers, with rates of smoking among 


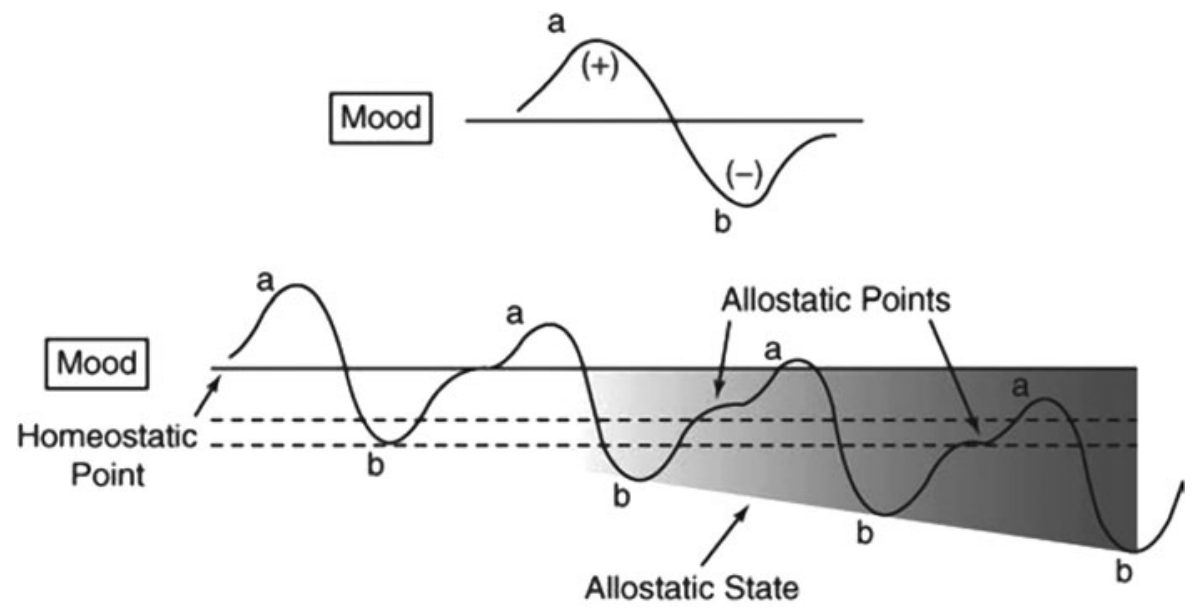

FIG. 1. Opponent process theory.

treatment-seeking pain patients ranging from $49 \%$ to $68 \%{ }^{41-44}$ Although a recent meta-analysis showed that nicotine can produce modest acute analgesia among humans, chronic cigarette smoking has been identified as a unique risk factor in the incidence and progression of several chronically painful conditions. ${ }^{45,46}$ In terms of using nicotine for pain relief, the experience of pain has been shown to be a potent motivator of smoking behavior, ${ }^{47}$ and pain patients have reliably endorsed smoking cigarettes to cope with pain. ${ }^{48}$ Commensurate with evidence of complex interrelations between pain and tobacco smoking, research has also shown that daily smokers are nearly five times more likely to meet pastyear diagnostic criteria for opioid abuse or dependence than never smokers. ${ }^{49}$

The aberrant use of opioid medications is a growing public health crisis, and factors that have been shown to confer heightened risk for prescription opioid misuse include the presence of chronic pain and co-occurring substance use and mood disorders. ${ }^{50-52}$ Opioid use accelerated in recent decades as a result of a social movement that cited cultural, societal, religious, and political attitudes as reasons for inadequate pain management. ${ }^{53}$ The result of the widespread increase in opioid prescribing in the United States was quadrupling of opioidcaused deaths over 15 years. ${ }^{54}$ One out of every 32 patients prescribed at least 200 morphine milligram equivalents per day died from chronic pain treatment. ${ }^{55}$

As with other short-acting, consciousness-altering drugs, opioids are regarded by many patients as the best pharmacotherapy for pain relief. However, despite beliefs to the contrary, opioids are not optimal pharmacotherapy for chronic pain. Koob and LeMoal's opponent process theory is one way to understand this phenomenon. ${ }^{56}$ Every dose of opioids helps pain, the "a" process. Over time, drivers of dysphoria: pain, anxiety, and depression, the " $b$ " process, overshoot the amelioration of pain (Fig. 1) Consistent with opponent process theory and emerging research on pain and substance use, an evolving allostatic load conceptualization of pain and addiction posits that chronic substance use (along with commensurate repeated opponent process cycles of substance-induced analgesia and withdrawal-induced hyperalgesia) can dysregulate overlapping neural substrates and homeostatic pain mechanisms to engender a persistent imbalance that favors pain facilitation. ${ }^{57}$

Gradually, opioid-induced hyperalgesia is induced. This is a state where pain increases and generalizes due to central sensitization. In response to this pain, prescribed or illegally obtained doses of opioids are increased in an attempt to override the pain system.

Cannabis is now being considered in the same way that opioids were decades ago, the combination of a drug class that is experienced as pain-relieving medications in the context of a social movement supporting the treatment for pain. We now move to an examination of the mechanisms of cannabis effects on pain and the limited number of studies available that examine the outcomes of pain treatment with cannabis.

The endocannabinoid system and mechanisms of pain reduction

Neural and nonneural cells in injured tissues produce arachidonic acid derivatives called endocannabinoids. ${ }^{58}$ 
They modulate neural conduction of pain signals by mitigating sensitization and inflammation through the activation of cannabinoid receptors that are also targeted by $\Delta^{9} \mathrm{THC}^{59} \mathrm{CB}_{1}$ receptors modulate neurotransmitter release in the brain and spinal cord. ${ }^{60} \mathrm{CB}_{1}$ receptors are also present in nociceptive and nonnociceptive sensory neurons of the dorsal root ganglion and trigeminal ganglion, ${ }^{61}$ as well as in defense cells such as macrophages, mast cells, and epidermal keratinocytes. ${ }^{62} \mathrm{CB}_{2}$ receptors are expressed at considerable levels in cells of hematopoietic origin. ${ }^{63}$ Few $\mathrm{CB}_{2}$ receptors are located in the brain, spinal cord, and dorsal root ganglion, but they increase in response to peripheral nerve damage. ${ }^{64}$ They regulate neuroimmune interactions and interfere with inflammatory hyperalgesia.

Endocannabinoids, anandamide, and 2-arachidonoylsn-glycerol (2-AG) are produced in injured tissues through distinct biochemical pathways to suppress sensitization and inflammation by activation of cannabinoid (CB) receptors. Anandamide can act as an autocrine or paracrine messenger and follows one of two pathways. In a reaction catalyzed by fatty acid amide hydrolase, it can be broken down to arachidonic acid and ethanolamine or, ${ }^{65}$ alternatively, it can be directly transformed by COX-2 into proalgesic prostamides. ${ }^{66}$ Anandamide mobilizes in response to inflammation and nerve injury and modulates nociceptive signals by activating local $\mathrm{CB}_{1}$ receptors. 2-AG is formed by the hydrolysis of phosphatidylinositol-4,5-biphosphate, a phospholipid at the center of a lipid pathway that produces numerous intracellular and transcellular messengers. ${ }^{65}$ It plays a prominent role in the descending modulation of pain during acute stress. ${ }^{67}$ Anandamide and 2-AG are recruited during tissue injury to provide a first response to nociceptive signals. Thus, understanding the function of endogenous cannabinoids helps explain the efficacy of exogenous cannabinoids, such as those found in the cannabis plant, in treating pain.

Therefore, the biologically hypothesized rationale for cannabinoid administration is whole-body exposure to exogenous cannabinoids to turn on pain inhibition. Of note, long-term studies of analgesia with exogenous cannabinoids would be necessary to adjudicate the question of whether pain could be continually suppressed in this manner, or whether the same hyperalgesic response to cannabinoids that is currently observed with opioids would ensue, another opponent process. Thus, physicians must be careful, just as with alcohol, nicotine, and opioids, about endorsing a drug where every use gives a subjective experience that pain is improved, and yet use of the drug over time has both hyperalgesic and potentially addictive properties.

\section{Cannabis and pain studies}

Results from studies evaluating cannabis pharmacotherapy for pain demonstrate the complex effects of cannabis-related analgesia. There are multiple randomized, controlled clinical trials that show cannabis as an effective pharmacotherapy for pain. ${ }^{68}$ However, further examination of pre-clinical studies of cannabis in pain models underscores the nuances of cannabis' analgesic effects. THC has been shown to produce analgesic and antihyperalgesic effects in animal models, ${ }^{69,70}$ and experimental research examining the effects of cannabis on human pain responding has focused either on healthy adults or clinical pain samples. For example, Wallace et al. tested the effects of smoked cannabis (low, medium, or high doses vs. inactive placebo) on intradermal capsaicin-induced pain responses using a randomized, double-blind, crossover trial in 15 healthy volunteers (mean age of $28.9 ; 58 \%$ male). ${ }^{71}$ Results indicated a significant decrease in pain with the medium cannabis dose and a significant increase in pain with the high dose. No differences were observed with the low cannabis dose, and there was no effect on the area of hyperalgesia at any dose. The authors concluded that there is likely a therapeutic window of modest analgesia for smoked cannabis.

Another experimental study with 18 healthy female volunteers tested the effects of orally administered cannabis extract (vs. active placebo) on sunburn and intradermal capsaicin pain responses using a double-blind, crossover trial. ${ }^{72}$ Results indicated that the cannabis extract did not produce any analgesic or antihyperalgesic effects. There was also some evidence of an unexpected hyperalgesic state in the cannabis group. These authors concluded that the utility of cannabis use for acute pain relief is limited by the poorly understood therapeutic window and the dose-dependent occurrence of psychotropic side effects.

In terms of clinical pain, a recent systematic review and meta-analysis of cannabinoids for medical use that examined 28 randomized trials among 2454 patients with chronic pain indicated that, compared with placebo, cannabinoids were associated with greater a reduction in pain ( $37 \%$ vs. $31 \%$; OR $1.41,95 \%$ CI 0.99 to 2.00 ) and greater average reduction in numerical pain ratings $(-0.46,95 \%$ $\mathrm{CI}-0.80$ to -0.11$).{ }^{73}$ Whiting et al. concluded that there was moderate evidence to support the use of cannabinoids for the treatment of chronic pain. In this review, 
neuropathy was the most commonly cited source of chronic pain. The majority of studies focused on testing the effects of plant-derived cannabinoids. Only 5 of the 28 trials assessed the effects of vaporized or smoked cannabis plant flower. Of note, cannabinoids were associated with an increased risk for short-term adverse events, including serious adverse events, compared to placebo.

One recent study not included in Whiting's metaanalysis was a placebo-controlled trial of inhaled aerosolized cannabis, which demonstrated a dose-dependent reduction in diabetic peripheral neuropathy spontaneous pain ratings among patients with treatment-refractory pain. ${ }^{74}$ Finally, and most recently, Wilsey et al. conducted a randomized, placebo-controlled crossover trial utilizing vaporized cannabis among 42 participants with central neuropathic pain related to spinal cord injury and disease ${ }^{75}$ Results indicated that vaporized cannabis flower reduced neuropathic pain scale ratings, but there was no evidence of a dose-dependent effect. These authors concluded that additional research is needed to examine how interactions among cannabinoids may influence analgesic responding.

Collectively, this research indicates that although the results of experimental studies with healthy adults are mixed, there is converging evidence to support the notion that cannabis can produce acute pain-inhibitory effects among individuals with chronic pain. This observation is consistent with determinations made by authors of the recent National Academies report on cannabis that there is "conclusive or substantial evidence" of benefit from cannabis or cannabinoids for chronic pain. However, it is important to also highlight their statement that more research is needed to better understand the efficacy, dose-response effects, routes of administration, and side effect profiles for cannabis products that are commonly used in the United States. ${ }^{8}$

\section{Clinical issues}

According to the DSM 5 heuristic, ${ }^{76}$ a diagnosis of cannabis use disorder (CUD) requires a pattern of cannabis use leading to clinically significant impairment or distress characterized by the presence of two or more of 11 prototypical symptoms within a 12-month period. These symptoms can be organized into three broad categories: (1) physical symptoms including craving, withdrawal, and tolerance, (2) use-induced psychosocial problems, and (3) increased drug-use and/or drug-seeking behavior. It has been estimated that one out of every 10 people who ever use cannabis will develop a CUD, ${ }^{77-79}$ and nationally representative U.S. data indicate that consequences con- sistent with CUD are endorsed by $\sim 30 \%$ of all current users. ${ }^{80}$ The cannabis withdrawal syndrome typically results from abrupt cessation with a time course that may persist for $\sim 14$ days following discontinuation (similar to tobacco withdrawal). ${ }^{81-83}$ Importantly, both acute intoxication and withdrawal frequently produce symptoms that feature prominently among those with chronic pain (i.e., mood disturbance and sleep problems). ${ }^{82}$

Consistent with previously published conceptualizations of interrelations between pain and substance use, ${ }^{39,40,84}$ pain and cannabis use may be expected to interact in the manner of a positive feedback loop, resulting in greater pain and the development or maintenance of CUD. Negative affect would also be hypothesized to play a key mechanistic role, which is consistent with the identification of negative affect as a principal component in theoretical conceptualizations of pain processing and addiction motivation. ${ }^{85,86}$ Over time, bidirectional relationships between pain and cannabis use may result in more severe functional impairment, greater paininduced motivation to use cannabis, and increased negative affect and sensitivity to pain during periods of cannabis abstinence. Furthermore, expectations that abstaining from cannabis may exacerbate both pain and negative affect could serve as important barriers to cannabis cessation.

One important implication of this conceptualization is that individuals with chronic pain may develop unique CUD profiles that require specialized treatment. For example, chronic pain patients who engage in treatment for CUD may benefit from taking additional measures to manage their pain during the early stages of cannabis abstinence. Similarly, patients receiving pain treatment may benefit from interventions that aim to reduce the use of cannabis for pain-coping purposes. Finally, given that pain motivates more than half of all annual physician visits in the United States, ${ }^{87}$ patients who present to primary care with co-occurring pain and cannabis use may benefit from an integrated treatment delivered within that setting. Additional research is needed to better understand the interplay of pain and cannabis use both over time and during the course of a cessation attempt. Clinicians may also consider the utility of sequential or integrated treatment for pain and CUD.

As cannabis is evaluated as pharmacotherapy and its use becomes more widespread, its significant side effects remain. Like other substances, there are potential adverse effects with acute and chronic use. Cognitive impairment can occur with both acute and chronic 
use, and adverse cognitive effects may be one area where the effects of chronic cannabis use could be worse than chronic opioid use. Although the acute effects of cannabis use, on driving for example, have received increasing attention with the implementation of medical and recreational cannabis policies, the effects of chronic use are better described.$^{88}$ Regular cannabis use, especially while the brain is under development, is associated with an increased risk of anxiety, depression, and psychotic illness, and cannabis can worsen the courses of these disorders. ${ }^{68}$ These associations are especially important given the common co-occurrence of chronic pain and psychiatric conditions. ${ }^{89}$ The implementation of medical and recreational cannabis policies offer an opportunity to collect longitudinal data on the effects of cannabis use. As we continue to collect such data, cannabis pharmacotherapy for pain management must be based upon thorough risk-benefit discussions.

\section{Cannabis and Opioid Interactions}

As more states introduce medical and recreational cannabis policies, we continue to learn more about the relationship between cannabis and opioids. Many patients have described a decreased need for prescription opioids after starting medical cannabis regimens. Many substances with addictive properties utilize common neural pathways, providing a theoretical basis for such anecdotes. Recently, rigorous studies have begun to provide evidence for these anecdotes as well. Bachhuber et al. described that states with medical cannabis laws had significantly lower annual opioid overdose mortality rates compared to states without medical cannabis. $^{90}$ This finding may be the result of patients with chronic pain initiating pharmacotherapy with medical cannabis, thereby lowering the need for opioid pharmacotherapy. Less reliance on opioid pharmacotherapy may in turn lead to fewer fatal opioid overdoses. A recent examination of Medicare claims data also showed that the use of prescription pain medications, including opioids, was significantly reduced in states following the implementation of medical cannabis laws. Finally, another study demonstrated that the percentage of drivers testing positive for opioids after traffic fatalities was significantly reduced in states with medical cannabis laws compared to states without such laws. ${ }^{91}$ Taken together, these studies provide initial support for medical cannabis being correlated with decreased opioid-induced mortality. Further studies are necessary to further elucidate the role of cannabis as a potentially safer alternative to opioids for pharmacological pain management.

\section{Conclusions}

This is a pivotal time in the history of cannabis and cannabinoid research. In the context of increasing debates on the merits of medical and recreational cannabis policies, we need a corresponding increase in cannabis research. Many advocates on either side of these debates appear content to promote their agendas without placing priority on funding and supporting research that would answer key questions about the safety of cannabis and its potential medical indications. The often contentious debate about the efficacy of cannabis pharmacotherapy for pain is an important example. There is evidence, although limited, to support the use of cannabis pharmacotherapy in certain clinical scenarios. For example, if a patient with chronic pain and their healthcare provider work together through first- and secondline treatment modalities without success, a trial of cannabis or a cannabinoid may be a reasonable next step. As cannabis use increases, additional research to support or refute the current evidence base is essential to attempt to answer the questions that so many healthcare professionals and patients are asking.

\section{Acknowledgment}

This study was supported by NIDA K99/R00 DA029115 (K.P.H.).

\section{Author Disclosure Statement}

No competing financial interests exist.

\section{References}

1. Russo EB. History of cannabis and its preparations in saga, science, and sobriquet. Chem Biodivers. 2007;4:1614-1648.

2. Savage SR, Romero-Sandoval A, Schatman M, et al. Cannabis in pain treatment: clinical and research considerations. J Pain. 2016;17:654-668.

3. National Conference of State Legislatures. 2016. State medical marijuana laws. November 9. Available at www.ncsl.org/research/health/statemedical-marijuana-laws.aspx (last accessed November 21, 2016).

4. Bestrashniy J, Winters KC. Variability in medical marijuana laws in the United States. Psychol Addict Behav. 2015;29:639-642.

5. Light MK, Orens A, Lewandowski B, et al. Market size and demand for marijuana in Colorado. The Marijuana Policy Group. 2014. Available at www.colorado.gov/pacific/sites/default/files/Market\%20Size\%20and\% 20Demand\%20Study,\%20July\%209,\%202014\%5B1\%5D.pdf (last accessed November 17, 2016).

6. Ilgen MA, Bohnert K, Kleinberg F, et al. Characteristics of adults seeking medical marijuana certification. Drug Alcohol Depen. 2013;132:654-659.

7. Sznitman SR, Bretteville-Jensen AL. Public opinion and medical cannabis policies: examining the role of underlying beliefs and national medical cannabis policies. Harm Reduct J. 2015;12:46.

8. National Academies of Sciences, Engineering, and Medicine. The health effects of cannabis and cannabinoids: the current state of evidence and recommendations for research. The National Academies Press: Washington, DC, 2017. 
9. Touw M. The religious and medicinal uses of cannabis in China, India and Tibet. J Psychoactive Drugs. 1981;13:23-34.

10. Li HL, Lin H. An archaeological and historical account of cannabis in China. Econ Bot. 1974;28:437-447.

11. Mikuriya TH. Marijuana in medicine: past, present and future. Calif Med. 1969;110:34-40.

12. Aldrich M. History of therapeutic cannabis. In: Mathre ML, eds. Cannabis in medical practice. McFarland: Jefferson, NC, 1997, pp. 35-55.

13. Fankhauser M. History of cannabis in Western Medicine. In: Grotenhermen F, Russo E, eds. Cannabis and Cannabinoids. Chapter 4. The Haworth Integrative Healing Press: New York, 2002, pp. 37-51.

14. Grinspoon L. Marihuana reconsidered. Harvard University Press: Cambridge, MA, 1971.

15. Grinspoon L, Bakalar JB. Marijuana: the forbidden medicine. Chapter 1. Yale Universty Press: New Haven, CT, 1993.

16. Substance Abuse and Mental Health Services Administration. Results from the 2015 national survey on drug use and health: detailed tables. Center for Behavioral Health Statistics and Quality: Rockville, MD, 2016.

17. Mechoulam RJ. Marijuana: chemistry, pharmacology and clinical effects. Academic Press: New York, 1973, pp. 2-99.

18. Mlezack R, Wall PD. Pain mechanisms: a new theory. Science. 1965;150:971-979.

19. IOM. Relieving pain in america: a blueprint for transforming prevention, care, education, and research. The National Academies Press: Washington, DC, 2011.

20. Tsang A, Von Korff $M$, Lee $S$, et al. Common chronic pain conditions in developed and developing countries: gender and age differences and comorbidity with depression-anxiety disorders. J Pain. 2008;9:883-891.

21. Turk DC, Rudy TE. Towards a comprehensive assessment of chronic pain patients. Behav Res Ther. 1987;25:237-249.

22. Arnold LM, Choy E, Clauw DJ, et al. Fibromyalgia and chronic pain syndromes: a white paper detailing current challenges in the field. Clin J Pain. 2016;32:737-746.

23. Shubayev VI, Kato K, Myers RR. Cytokines in pain. In: Kruger L, Light AR, eds. Translational pain research: from mouse to man. Chapter 8. CRC Press/Taylor \& Francis: Boca Raton, FL, 2010. Available at www.ncbi.nlm.nih.gov/books/NBK57275 (last accessed May 16, 2017).

24. Koenig J, Werdenhausen R, Linley JE, et al. Regulation of the NA(v)1.7: a conserved SCN9A natural antisense transcript expressed in dorsal root ganglia. PLOS One. 2015;10:e0128830.

25. Clauw DJ. Fibromyalgia: a clinical review. JAMA. 2014;311:1547-1555.

26. Kremer M. Antidepressants and gabapentinoids in neuropathic pain: mechanistic insights. Neuroscience. 2016;338:183-206.

27. Cheng Y, Chen C, Lin CP, et al. Love hurts: an fMRI study. Neuroimage. 2010;51:923-929.

28. Platts-Mills TF, Hunold KM, Bortsov AV, et al. More educated emergency department patients are less likely to receive pain medication. Pain. 2012;153:967-973.

29. Johnson B, Mosri D. The neuropsychoanalytic approach: using neuroscience as the basic science of psychoanalysis. Front Psychol. 2016;7:1459.

30. Johnson B, Faraone SV. Outpatient detoxification completion and one month outcomes for opioid dependence: a preliminary open label study of a neuropsychoanalytic treatment in pain patients and addicted patients, Neuropsychoanalysis. 2013;15:145-160.

31. Solomon DH, Rassen JA, Glynn RJ, et al. The comparative safety of analgesics in older adults with arthritis. Arch Intern Med. 2010;170:1968-1978.

32. Zale EL, Maisto SA, Ditre, JW. Interrelations between pain and alcohol: an integrative review. Clin Psychol Rev. 2015;37:57-71.

33. Larson MJ, Paasche-Orlow M, Cheng DM, et al. Persistent pain is associated with substance use after detoxification: a prospective cohort analysis. Addiction. 2007;102:752-760.

34. Demyttenaere K, Bruffaerts $\mathrm{R}$, Lee $\mathrm{S}$, et al. Mental disorders among persons with chronic back or neck pain: results from the World Mental Health Surveys. Pain. 2007;129:332-342.

35. Strine TW, Hootman JM. US national prevalence and correlates of low back and neck pain among adults. Arthritis Rheum. 2007;57:656-665.

36. Von Korff M, Crane P, Lane M, et al. Chronic spinal pain and physicalmental comorbidity in the United States: results from the national comorbidity survey replication. Pain. 2005;113:331-339.

37. National Institute on Alcohol Abuse and Alcoholism. Alcohol overdose: the dangers of drinking too much. 2015. Available at https:// pubs.niaaa.nih.gov/publications/alcoholoverdosefactsheet/overdose Fact.pdf (last accessed May 16, 2017).

38. Jochum T, Boettger MK, Burkhardt C, et al. Increased pain sensitivity in alcohol withdrawal syndrome. Eur J Pain. 2010;14:713-718.

39. Ditre JW, Brandon TH, Zale EL, et al. Pain, nicotine, and smoking: research findings and mechanistic considerations. Psychol Bull. 2011;137:10651093.

40. Zale EL, Maisto SA, Ditre JW. The role of anxiety and depression in bidirectional relations between pain and tobacco smoking. Behav Modif. 2016;40:7-28.

41. Hooten WM, Shi Y, Gazelka HM, et al. The effects of depression and smoking on pain severity and opioid use in patients with chronic pain. Pain. 2011;152:223-229.

42. Zvolensky MJ, McMillan KA, Gonzalez A, et al. Chronic musculoskeletal pain and cigarette smoking among a representative sample of Canadian adolescents and adults. Addict Behav. 2010;35:1008-1012.

43. Michna E, Ross EL, Hynes WL, et al. Predicting aberrant drug behavior in patients treated for chronic pain: importance of abuse history. J Pain Symptom Manage. 2014;28:250-258.

44. Jamison RN, Stetson BA, Parris WC. The relationship between cigarette smoking and chronic low back pain. Addict Behav. 1991;16:103-110.

45. Ditre JW, Heckman BW, Zale EL, et al. Acute analgesic effects of nicotine and tobacco in humans: a meta-analysis. Pain. 2016;157:1373-1381.

46. Shiri R, Karppinen J, Leino-Arjas $P$, et al. The association between smoking and low back pain: a meta-analysis. Am J Med. 2010;123:e7-e35.

47. Ditre JW, Brandon TH. Pain as a motivator of smoking: effects of pain induction on smoking urge and behavior. J Abnorm Psychol. 2008; 117:467-472.

48. Patterson AL, Gritzner S, Resnick MP, et al. Smoking cigarettes as a coping strategy for chronic pain is associated with greater pain intensity and poorer pain-related function. J Pain. 2012;13:285-292.

49. Zale EL, Dorfman ML, Hooten WM, et al. Tobacco smoking, nicotine dependence, and patterns of prescription opioid misuse: results from a nationally representative sample. Nicotine Tob Res. 2015;17:1906-1103.

50. ONDCP. Epidemic: responding to America's prescription drug abuse crisis. 2011. Available at www.whitehouse.gov/sites/default/files/ondcp/ issues-content/prescription-drugs/rx_abuse_plan.pdf (last accessed July 7, 2014).

51. Sehgal N, Manchikanti L, Smith HS. Prescription opioid abuse in chronic pain: a review of opioid abuse predictors and strategies to curb opioid abuse. Pain Physician. 2012;15:ES67-ES92.

52. Turk DC, Swanson KS, Gatchel RJ. Predicting opioid misuse by chronic pain patients: a systematic review and literature synthesis. Clin J Pain. 2008;24:497-508.

53. Brennan F, Carr DB, Cousins M. The role of opioids in pain management Anesth Analg. 2007;105:205-221.

54. Calcaterra S, Glanz J, Binswanger IA. National trends in pharmaceutical opioid related overdose deaths compared to other substance related overdose death: 1999-2009. Drug Alcohol Depend. 2013;131:263-270.

55. Freiden TR, Houry D. Reducing the risks of relief-the CDC opioid prescribing guideline. N Engl J Med. 2016;374:1501-1504.

56. Koob GF, LeMoal M. Drug addiction, dysregulation of reward and allostasis. Neuropsychopharmacology. 2001;24:98-129.

57. Egli M, Koob GF, Edwards S. Alcohol dependence as a chronic pain disorder. Neurosci Biobehav Rev. 2012;36:2179-2192.

58. Piomelli D, Sasso O. Peripheral gating of pain signals by endogenous lipid mediators. Nat Neurosci. 2014;17:164-174.

59. Rice AS. Cannabinoids and pain. Cuurr Opin Investig Drugs. 2001;2:399414

60. Castillo PE, Younts TJ, Chavez AE, et al. Endocannabinoid signaling and synaptic function. Neuron. 2012;76:70-81.

61. Price TJ, Helesic G, Parghi D, et al. The neuronal distribution of cannabinoid receptor type 1 in the trigeminal ganglion of the rat. Neuroscience. 2003;120:155-162.

62. Sugawara K, Zakany N, Hudt T, et al. Cannabinoid receptor 1 controls human mucosal-type mast cell degranulation and maturation in situ. J Allergy Clin Immunol. 2013;132:182-193.

63. Stander S, Schemlz M, Metze D, et al. Distribution of cannabinoid recepto 1 (CB1) and 2 (CB2) on sensory nerve fibers and adnexal structures in human skin. J Dermatol Sci. 2005;38:177-188.

64. Guindon J, Hohmann AG. The endocannabinoid system and pain. CNS Neurol Disord Drug Targets. 2009;8:403-421. 
65. Piomelli D, Astarita G, Rapaka R. A neuroscientist's guide to lipidomics. Nat Rev Neurosci. 2007;8:743-754.

66. Massaro M, Martinelli R, Gatta V, et al. Transcriptome-based identification of new anti-anti-inflammatory and vasodilating properties of the $n-3$ fatty acid docosahexaenoic acid in vascular endothelial cell under proinflammatory conditions. PLoS One. 2016;10:e0129652.

67. Hohmann AG, Suplita RL, Bolton NM, et al. An endocannabinoid mechanism for stress-induced analgesia. Nature. 2005;435:1108-1112.

68. Hill KP. Medical marijuana for treatment of chronic pain and other medical and psychiatric problems, a clinical review. JAMA. 2015:313:2474-2483.

69. Lim G, Sung B, Ji RR, et al. Upregulation of spinal cannabinoid-1-receptors following nerve injury enhances the effect of WIN55,212-2 on neuropathic pain behaviour in rats. Pain. 2003;105:275-283.

70. Johanek LM, Heitmiller DR, Turner M, et al. Cannabinoids attenuate capsaicin-evoked hyperalgesia through spinal and peripheral mechanisms. Pain. 2001;93:303-315.

71. Wallace M, Schulteis $\mathrm{G}$, Atkinson $\mathrm{JH}$, et al. Dose-dependent effects of smoked cannabis on capsaicin-induced pain and hyperalgesia in healthy volunteers. Anesthesiology. 2007;107:785-796.

72. Kraft B, Frickey NA, Rainer M, et al. Lack of analgesia by oral standardized cannabis extract on acute inflammatory pain and hyperalgesia in volunteers. Anesthesiology. 2008;109:101-110.

73. Whiting PF, Wolff RF, Deshpande S, et al. Cannabinoids for medical use: a systematic review and meta-analysis. JAMA. 2015;313:2456-2473.

74. Wallace MS, Marcotte TD, Umlauf A, et al. Efficacy of inhaled cannabis on painful diabetic neuropathy. J Pain. 2015;16:616-627.

75. Wilsey BL, Deutsch R, Samara E, et al. A preliminary evaluation of the relationship of cannabinoid blood concentrations with the analgesic response to vaporized cannabis. J Pain Res. 2016;9:587-598.

76. APA. Diagnostic and statistical manual of mental disorders, 5 th ed. Washington, DC, 2013

77. Florez-Salamanca L, Secades-Villa R, Hasin DS, et al. Probability and predictors of transition from abuse to dependence on alcohol, cannabis, and cocaine: results from the National Epidemiologic Survey on Alcohol and Related Conditions. Am J Drug Alcohol Abuse. 2013;39 168-179.

78. Hall WD, Pacula RL. Cannabis use and dependence: public health and public policy. Cambridge University Press: Cambridge, UK, 2003.

79. Lopez-Quintero C, Perez de los Cobos J, Hasin DS, et al. Probability and predictors of transition from first use to dependence on nicotine, alcohol, cannabis, and cocaine: results of the National Epidemiologic Survey on Alcohol and Related Conditions (NESARC). Drug Alcohol Depend. 2011;115:120-130.

80. Compton WM, Grant BF, Colliver JD, et al. Prevalence of marijuana use disorders in the United States: 1991-1992 and 2001-2002. JAMA. 2004;291:2114-2121.
81. Allsop DJ, Copeland J, Norberg MM, et al. Quantifying the clinical significance of cannabis withdrawal. PLoS One. 2012;7:e44864.

82. Budney AJ, Hughes, JR, Moore BA, et al. Review of the validity and significance of cannabis withdrawal syndrome. Am J Psychiatry. 2004;161:1967-1977.

83. Levin $\mathrm{KH}$, Copersino ML, Heishman SJ, et al. Cannabis withdrawal symptoms in non-treatment-seeking adult cannabis smokers. Drug Alcohol Depend. 2010;111:120-127.

84. Zale EL, Maisto SA, Ditre JW. Interrelations between pain and alcohol: an integrative review. Clin Psychol Rev. 2015;37:57-71.

85. Wade JB, Dougherty LM, Archer CR, et al. Assessing the stages of pain processing: a multivariate analytical approach. Pain. 1996;68:157-167.

86. Baker TB, Piper ME, McCarthy DE, et al. Addiction motivation reformulated: an affective processing model of negative reinforcement. Psychol Rev. 2004:111:33-51.

87. Turk DC, Melzack R. The measurement of pain and the assessment of people experiencing pain. In Turk DC, Melzack R, eds. Handbook of pain assessment, 3rd ed. The Guilford Press: New York, 2011, pp. 3-18.

88. Sewell RA, Poling J, Sofuoglu M. The effect of cannabis compared with alcohol on driving. Am J Addict. 2009;18:185-193.

89. Workman EA, Hubbard JR, Felker BL. Comorbid psychiatric disorders and predictors of pain management program success in patients with chronic pain. Prim Care Companion J Clin Psychiatry. 2002;4:137-140.

90. Bachhuber MA, Saloner B, Cunningham CO, et al. Medical cannabis laws and opioid analgesic overdose mortality in the United States, 1999-2010. JAMA Intern Med. 2014;174:1668-1673.

91. Bradford AC, Bradford DW. Medical marijuana laws reduce prescription medication use in Medicare part D. Health Affairs. 2016;35:1230-1236.

Cite this article as: Hill KP, Palastro MD, Johnson B, Ditre JW (2017)

Cannabis and pain: a clinical review, Cannabis and Cannabinoid

Research 2:1, 96-104, DOI: 10.1089/can.2017.0017.

$\begin{aligned} & \text { Abbreviations Used } \\ & 2-A G=2 \text {-arachidonoyl-sn-glycerol } \\ & \mathrm{AUD}=\text { alcohol use disorder } \\ & \mathrm{COX}=\text { cyclooxygenase } \\ & \mathrm{CUD}=\text { cannabis use disorder } \\ & \mathrm{NSAID}=\text { nonsteroidal anti-inflammatory drugs } \\ & \mathrm{THC}=\text { tetrahydrocannabinol }\end{aligned}$

Cannabis and

Cannabinoid

Research
- Immediate, unrestricted online access

- Rigorous peer review

- Compliance with open access mandates

- Authors retain copyright

- Highly indexed

- Targeted email marketing

liebertpub.com/can 